Bond University

Research Repository

\title{
The relationship between children's motor proficiency and health-related fitness
}

Milne, Nikki; Leong, Gary M.; Hing, Wayne

Published in:

Journal of Paediatrics and Child Health

DOI:

10.1111/jpc.13236

Link to output in Bond University research repository.

Recommended citation(APA):

Milne, N., Leong, G. M., \& Hing, W. (2016). The relationship between children's motor proficiency and healthrelated fitness. Journal of Paediatrics and Child Health, 52(8), 825-831. https://doi.org/10.1111/jpc.13236

\footnotetext{
General rights

Copyright and moral rights for the publications made accessible in the public portal are retained by the authors and/or other copyright owners and it is a condition of accessing publications that users recognise and abide by the legal requirements associated with these rights.
}

For more information, or if you believe that this document breaches copyright, please contact the Bond University research repository coordinator. 
Title: The relationship between children's motor proficiency and health-related fitness

Type of Article: Original Article

Authors: Nikki Milne ${ }^{1}$, Gary M. Leong², Wayne Hing

\section{Affiliations:}

${ }^{1}$ Faculty of Health Sciences and Medicine, Bond Institute of Health and Sport, Bond University, Gold Coast, Australia.

${ }^{2}$ Institute for Molecular Bioscience, The University of Queensland, and Department of Paediatric Endocrinology and Diabetes, Lady Cilento Children’s Hospital, QLD, Australia.

\section{Author Details:}

1. Nikki Milne, Assistant Professor of Physiotherapy, Bond Institute of Health and Sport, Bond University, QLD, Australia. (PhD, MPhty, MEd (ECE), BEd, BExSc)

2. Gary M. Leong, Associate Professor, School of Medicine and Adjunct Research Fellow, Institute for Molecular Bioscience, The University of Queensland, and Department of Paediatric Endocrinology and Diabetes, Lady Cilento Children’s Hospital, QLD, Australia (MBBS, FRACP, PhD)

3. Wayne Hing, Professor of Physiotherapy, Bond Institute of Health and Sport, Bond University, QLD, Australia. (PhD, MHSc (Hons), ADP (OMT), DipMT, DipPhys, DipAcu).

Address correspondence to: Nikki Milne, Bond Institute of Health and Sport, Health Sciences and Medicine Faculty, Bond University, Robina QLD 4226, Australia. [nmilne@bond.edu.au], Ph: +61 75595 4155, Fax: +61 755953524

Short title: Motor skills and health-related fitness.

Word Count: Abstract - 236, Manuscript - 3123

Tables: 4

Figures: 1 


\begin{abstract}
Aims: The overall purpose of this study was to examine the relationship between motor proficiency and health-related fitness in children. In addition the study aimed to determine if particular combinations of motor skills have a stronger relationship with individual healthrelated fitness measures.
\end{abstract}

Methods: Seventy-seven children (F:28, M:49) (Mean Age: 11.19 \pm 2.74 yr) participated in this prospective cohort study. Physical measures included: Motor proficiency (Bruininks-Oseretsky Test of Motor Proficiency, $2^{\text {nd }}$ Edition), Body Mass Index (BMI), waist circumference (WC), blood pressure (BP), heart rate (HR), $\mathrm{VO}^{2}$ peak (mL/kg/min).

Results: After factoring in age; motor proficiency as a combined total score, had a strong negative relationship with the health-related fitness measures of BMI $\left(r^{2}=0.62, p<0.001\right)$ and waist circumference $\left(\mathrm{r}^{2}=0.72, \mathrm{p}<0.001\right)$ and a strong positive relationship with $\mathrm{VO}_{2}$ peak $\left(\mathrm{r}^{2}=\right.$ $0.78, \mathrm{p}=0.002)$. Children with lower motor proficiency $\left(\leq 25^{\text {th }}\right.$ percentile) had a significantly larger mean waist circumference $(\mathrm{M}=13.85 \mathrm{~cm}, 95 \% \mathrm{CI}[2.05,25.66], \mathrm{p}=0.01)$, heavier weight $(\mathrm{M}=22.17 \mathrm{~kg}, 95 \% \mathrm{CI}[2.44,41.91], \mathrm{p}=0.02)$ and higher BMI $\left(\mathrm{M}=5.10 \mathrm{~kg} / \mathrm{m}^{2}, 95 \%\right.$ CI $[0.33$, 9.87], $\mathrm{p}=0.03)$ than children with higher motor proficiency $\left(\leq 75^{\text {th }}\right.$ percentile $)$.

Conclusions: Motor proficiency, once corrected for age, is significantly related to a number of health-related measures in children and should therefore be considered a focus for investigation for children with poor health-related fitness (e.g. high BMI and WC percentiles or low cardiorespiratory fitness), as motor incompetence could be an underlying contributing factor to a child's poor physical health.

Key Words: Motor skills, Children, Waist Circumference, Blood Pressure, Fitness, Health. 


\section{What is already known on the topic?}

1. The physical fitness of children and adolescents internationally has been declining over the past 30 years.

2. In order for children to be physically fit, they need to be physically active.

3. To be physically active children require the combined attributes of both health-related fitness

(e.g. cardiorespiratory endurance, heart rate and blood pressure responses to exercise and body composition) and performance-related fitness (e.g. motor proficiency)

\section{What this study adds?}

1. Motor proficiency, after controlling for age and gender is negatively associated with healthrelated measures including resting systolic and diastolic BP, weight, BMI and WC and has a positive relationship with cardiorespiratory fitness $\left(\mathrm{VO}_{2}\right.$ peak).

2. Strength and Running Speed and Agility were the strongest contributors to the relationship between motor proficiency and the health-related measures of WC, BMI and cardiorespiratory fitness $\left(\mathrm{VO}_{2}\right.$ peak). 


\section{Introduction}

The physical fitness of children and adolescents internationally has been declining over the past 30 years with adiposity increasing $(1,2)$. In order for children to be physically fit, they need to be physically active (3) and to do this children require the combined attributes of both healthrelated fitness (e.g. cardiorespiratory endurance, heart rate and blood pressure responses to exercise and body composition) and performance-related fitness (e.g. motor proficiency) (4).

Children and adolescents with lower motor proficiency have a significantly higher Body Mass Index (BMI) compared to those with high motor proficiency (5). Additionally, motor skills have been shown to be significant predictors of BMI, indicating that individuals with low motor competence are more likely to have compromised health-related fitness (6,7). In addition to BMI, waist circumference (WC) has previously been shown to be a significant predictor for ability to perform fundamental motor skills such as running, jumping, catching, throwing, striking and kicking (8). Furthermore, children with poor motor proficiency are more likely to choose a less active lifestyle in order to avoid the movement difficulties they possess (9). This may create a vicious cycle of further sedentary behaviour, decreased physical activity, and worsening states of fitness, including cardiorespiratory fitness. Higher motor proficiency is associated with increased enjoyment of physical activity (10), thus one could reasonably predict that a child with good motor skills would be more likely to be physically active and therefore possess enhanced health-related fitness (i.e. higher cardiorespiratory fitness, with BMI and WC in the 'healthy' categories). However, no studies to date have assessed the relationship between motor proficiency, using an internationally recognised and standardised motor assessment tool, and health-related fitness (including a direct measure of cardiorespiratory fitness, such as $\mathrm{VO}^{2}$ peak) in typically developing Australian children.

This study therefore aimed to: 1) examine the relationship between motor proficiency and health-related fitness in a general school-based cohort of children; 2) determine if the 
relationship differs for children with lower motor proficiency compared to children with higher motor proficiency and; 3) determine if particular combinations of motor skills have a stronger relationship with individual health-related fitness measures.

\section{Materials and Methods}

\section{Participants}

Children aged 5-17 years ( $\mathrm{n}=77)$ living in Queensland, Australia were recruited from the general population via advertisement to local schools, where a flyer was distributed to students by their classroom teachers. Inclusion criteria required children to be attending school and to be medically well at the time of assessment. Children were excluded from the study if they had an underlying medical condition e.g. orthopaedic or neurological conditions that limited their mobility and prevented completion of the standardised motor assessments. Informed consent and parent completed medical history forms were sent with an explanatory statement to the parents of the children volunteering for the study. Children were subsequently offered appointments to complete the research activities either at Bond University or at their school.

\section{Experimental Design}

A prospective cohort study design was implemented for this study with children ( $\mathrm{n}=\mathrm{F}: 28$;

M:49). Each child was seen for a single 2 hour visit either at the university research labs or at their school, to complete the health and motor proficiency measures. After familiarisation with the experimental design and study equipment, resting heart rate (HR) and blood pressure (BP) as well as anthropometric measures of height, weight and waist circumference (WC) were measured for each child before they completed the motor assessment. Twenty-four (31\%) ( $\mathrm{n}=\mathrm{F}: 6 ; \mathrm{M}: 18$ ) participants also consented to complete an incremental exercise test to volitional fatigue to determine their peak oxygen uptake $\left(\mathrm{VO}_{2}\right.$ peak) as a direct measure of cardiorespiratory fitness. Bond University Human Research Ethics Committee (BUHREC) approved the experimental protocols for the present study which conform to the provisions of 
the Declaration of Helsinki.

\section{Protocols}

\section{Health-related Measures}

After 10 minutes of quiet rest, HR and BP were measured in a seated position using a portable self-inflating blood pressure monitor (Omron T9P, Kyoto, Japan). Height, weight and WC measurements were taken individually behind a privacy screen, to prevent other children observing the measures. Standing height was measured barefooted at the end of tidal inspiration on a solid surface using a tape measure to the nearest $0.5 \mathrm{~cm}$. Weight was measured with light clothing on (e.g. shirt and shorts), using calibrated digital weight scales (HD-366, Tanita Corporation, Tokyo, Japan). Height and weight measurements were used to calculate BMI, including percentiles and Z scores, using CDC growth charts (11). WC was measured to the nearest $0.5 \mathrm{~cm}$ at the height of the umbilicus.

\section{Motor Skill Proficiency}

The Bruininks Oseretsky Test of Motor Proficiency, $2^{\text {nd }}$ Edition (BOT2) is a valid and reliable diagnostic and evaluative tool (12) that was used to assess motor proficiency of all participants. The BOT2 includes a number of subtests which represent fine and gross motor skills that have a relationship to functional activities in the domains of postural control, locomotion and object manipulation: Fine Motor Precision and Fine Motor Integration Total Point Scores (TPS) combine to make up the Fine Manual Control scale score; Manual Dexterity and Upper Limb Coordination TPS combine to make up the Manual Coordination scale score; Bilateral Coordination and Balance TPS combine to make up the Body Coordination scale score; Running Speed and Agility and Strength TPS combine to make up the Strength and Agility scale score. These scale scores combine to make up the Standard Scores (SS) which take into account age and gender and are totaled to make up the Total Motor Proficiency SS. All Standard Scores are converted to a percentile rank. The composite structure for the BOT2 uses 
standardised factor loadings based on intercorrelation coefficients of Subtest Scale Scores to Composite Standard Scores across three age ranges. The correlation between the Total Motor Standard Score and the Subtest Scale Scores range from r=0.67 - 0.73 (Fine Manual Control), $\mathrm{r}=0.76-0.77$ (Manual Coordination), $\mathrm{r}=0.73-0.79$ (Body Coordination) and $\mathrm{r}=0.78-0.80$ (Strength and Agility) suggesting that each motor domain has relatively equal contribution to the Total Motor Standard Score. Standardised instructions and scoring methods were applied in the assessment process as per the BOT2 assessment manual (12), with the exception of the order of testing, which was scheduled around cardiorespiratory fitness testing for those who participated in this measure. The authors acknowledge that there is a high level of agreement between the BOT2 Short Form (a screening tool to reflect motor proficiency) and BOT2 Total Motor Composite Scores (12). However, for this study the complete BOT2 assessment was chosen over the BOT2 short form or other validated motor assessments, as it provides data on a wider set of fine and gross motor subtests than other motor assessments. This allowed the research team to thoroughly address the third study aim; to determine if particular combinations of motor skills have a stronger relationship with individual health-related fitness measures.

\section{Determination of peak oxygen uptake $\left(\mathrm{VO}_{2}\right.$ peak)}

To determine peak oxygen uptake $\left(\mathrm{VO}_{2}\right.$ peak $)$, participants $(\mathrm{n}=24)$ performed an incremental exercise test to volitional fatigue on a motor-driven treadmill ('Valiant'; Lode B.V., Groningen, Netherlands). A predetermined preferred walking speed of $4.0-5.0 \mathrm{~km} / \mathrm{h}$ at $0 \%$ grade for $4 \mathrm{~min}$ was used to commence the test, before increasing the speed every $60 \mathrm{~s}$ until the participant achieved a previously determined ideal running speed $(6.0-8.0 \mathrm{~km} / \mathrm{h})$. For younger children a $1 \%$ increase and for adolescents a $2 \%$ increase in treadmill grade was introduced every $60 \mathrm{~s}$ until participant’s demonstrated volitional fatigue. Cardiac rhythm using a 12-lead ECG (Cardio Perfect, Welch Allyn Inc., Skaneateles Falls, USA) was monitored throughout the test and brachial artery BP was measured and recorded every 3 min. A calibrated open-circuit metabolic measurement system (Ultima CPX, Medical Graphics Corporation, St Paul, USA) 
was used to measure breath-by-breath values for oxygen uptake $\left(\mathrm{VO}_{2}\right)$, carbon dioxide output $\left(\mathrm{VCO}_{2}\right)$, and minute expired ventilation. The average of the two highest consecutive $30 \mathrm{~s}$ values measured before volitional fatigue were used to determine peak exercise values.

\section{Data Analysis}

Means and standard deviations were calculated for age and all health-related and motor performance-related measures for the total study group and four subgroups that were determined according to motor proficiency quartiles (BOT2 Standard Scores sorted into quartiles). Independent $t$ tests were used to assess differences in descriptive characteristics and health and performance-related fitness measures between boys and girls. Analysis of variance (1-way ANOVA) was used to determine differences in health-related measures between the four motor proficiency quartile subgroups using Sidaks post-hoc analysis to determine the point of difference if it occurred. Pearson's product moment correlations were computed to assess the relationship between health-related measures and motor proficiency for the total group and individually for the $1^{\text {st }}$ (lowest) and $4^{\text {th }}$ (highest) motor proficiency quartile subgroups. Multiple regression analysis was used to determine the strength of the relationship between certain models of motor proficiency and health measures when age and gender were factored into the analysis. Statistics were analysed with SPSS for Windows (Version 21.0) with a significance level set at $\mathrm{p}<0.05$.

\section{Results}

Seventy-seven children (F:28, M:49, Mean Age: 11.19 \pm 2.74 yr) participated in this study with a mean BMI in the 'healthy-weight' category but ranging from underweight $\left(<5^{\text {th }}\right.$ percentile) $(n=3,3.9 \%)$ to morbidly obese $\left(>99^{\text {th }}\right.$ centile) $(n=1,1.3 \%)$. The majority $(n=59,76.6 \%)$ were in the healthy weight range with eight (10.4\%) overweight and seven (9.1\%) obese/morbidly obese. The mean motor proficiency of participants was in the 'average' range with a mean peak 
oxygen uptake of $44.13 \pm 13.03 \mathrm{~mL} / \mathrm{kg} / \mathrm{min}$. No children were excluded from the study. Two of the male participants had a diagnosis of Autistic Spectrum Disorder (ASD), classified as 'mild' by their parents. The health-related fitness characteristics of all study participants are provided in Table 1 , including those in the $1^{\text {st }}$ (lowest) and $4^{\text {th }}$ (highest) motor quartile groups. Significant differences existed between boys and girls in the total group for age $(\mathrm{t}=-2.073$, $\mathrm{DF}=75, \mathrm{p}=0.042$ ), height, weight, HR and systolic BP but not BMI, WC or diastolic BP (see Table 1). There was no significant difference between girls and boys for $\mathrm{VO}_{2}$ peak $(\mathrm{t}=-0.622$, $\mathrm{DF}=22, \mathrm{p}=0.54)$.

A one-way ANOVA with Sidaks post-hoc analysis revealed no significant differences between participants in the $1^{\text {st }}$ (lowest) motor quartile group and the $4^{\text {th }}$ (highest) motor quartile group for resting HR, BP or height (Table 1.) Additionally there were no significant differences between these subgroups for age $(\mathrm{p}=0.33)$ or $\mathrm{VO}_{2}$ peak $(\mathrm{p}=0.21)$. However, participants in the $1^{\text {st }}$ motor quartile group had significantly larger WC, heavier weight and higher BMI than participants in the $4^{\text {th }}$ motor quartile group. Figure 1 outlines the variation in mean WC and BMI for participants in each of the motor quartile groups.

Motor performance-related fitness characteristics of study participants are reported in Table 2. No significant differences existed between boys and girls for any of the BOT2 Total Point Scores.

Table 3 presents Pearson’s product moment correlations between motor proficiency (BOT2 Standard Scores for fine and gross motor skills) and health-related fitness measures for the total group and the $1^{\text {st }}$ motor quartile subgroup. For children in the $4^{\text {th }}$ Motor Quartile group, a small negative relationship was found between WC and Total Motor Proficiency SS ( $r=-0.341$, $\mathrm{p}=0.048$ ). No other significant relationships between health-related fitness measures and motor proficiency (BOT2 Standard Scores) were observed for the children in the $4^{\text {th }}$ motor quartile 
group. Pearson's correlations were also undertaken to assess the relationship between the BOT2 Standard Scores and $\mathrm{VO}^{2}$ peak (mL/kg/min) for those who completed the incremental exercise test ( $\mathrm{n}=24$, Mean BMI Percentile=53.86 \pm 33.08 , Mean BMI Z score $=0.19 \pm 1.37$, Mean Total Motor Percentile Rank=53.88 \pm 32.53 ). Significant positive correlations existed between Total Motor Proficiency SS and $\mathrm{VO}^{2}$ peak $(\mathrm{mL} / \mathrm{kg} / \mathrm{min})(\mathrm{r}=0.418, \mathrm{p}=0.042)$ as well as the Strength and Agility SS and $\mathrm{VO}^{2}$ peak $(\mathrm{mL} / \mathrm{kg} / \mathrm{min})(\mathrm{r}=0.630, \mathrm{p}=0.001)$. This relationship strengthened considerably when examined for children in the $1^{\text {st }}$ Motor Quartile Group $(n=6)$, ( $r=0.948, p=0.004)$. Additionally, a significant negative relationship was revealed between Fine Manual Control SS and VO²peak ( $\mathrm{r}=-0.970, \mathrm{p}=0.001)$ for children in the $1^{\text {st }}$ Motor Quartile group. No significant difference was found for age $(t=-3.088, D F=75, p=0.375)$, Total Motor Proficiency $(t=1.700, D F=75, p=0.195)$ or $B M I$ percentile $(t=-0.659, D F=75, p=0.659)$ for children who completed $\mathrm{VO}^{2}$ peak testing compared to those who did not.

Multiple regression analysis was used to examine the contribution of age and gender to the relationship between motor proficiency (BOT2 Scores) and health-related fitness and these results are provided in Table 4. Although a model of combined BOT2 TPS + Age + Gender, was found to have the strongest relationship with the independent measures of WC, BMI and $\mathrm{VO}^{2}$ peak, the influence of gender to these relationships was not significant (WC: $\mathrm{p}=0.148$, BMI: $\mathrm{p}=0.079, \mathrm{VO}^{2}$ peak: $\mathrm{p}=0.291$ ) and gender could therefore be removed from the model with negligible effect (see Table 4). Additionally, the influence of individual fine motor total point scores to these relationships were not significant (WC: Fine Motor Precision p=0.665, WC: Fine Motor Integration: p=0.644; BMI: Fine Motor Precision p=0.681, BMI: Fine Motor Integration $\mathrm{p}=0.715$; $\mathrm{VO}^{2}$ peak: Fine Motor Integration $\mathrm{p}=0.831, \mathrm{VO}^{2}$ peak: Fine Motor Precision $\mathrm{p}=0.741$ ), suggesting that fine motor skills had a negligible effect on the relationship between motor proficiency and health-related fitness. Notably, the relationship between the health-related fitness measures and a combined model of Strength TPS and Running Speed and Agility TPS + 
Age, was almost as strong as the model that included all motor subtests (combined BOT2 TPS) (see Table 4).

\section{Discussion}

The present study aimed to determine if a relationship existed between motor proficiency and measures of health-related fitness in children and if so, did the relationship differ for children with lower motor proficiency compared to those with higher motor proficiency. The final of our study aims was to determine if particular combinations of motor skills had a stronger relationship with individual health-related fitness measures.

The results of this study indicate that total motor proficiency (inclusive of fine and gross motor skills), after controlling for age and gender is negatively associated with health-related measures including resting systolic and diastolic BP, weight, BMI and WC and has a positive relationship with cardiorespiratory fitness ( $\mathrm{VO}_{2}$ peak). These results address the first of the study aims. When the relationships were examined for children with a total motor proficiency equal to or below the $25^{\text {th }}$ percentile, the relationships strengthened considerably for all of these healthrelated measures, with the exception of resting diastolic BP, addressing the second of the study aims and suggesting that children with lower motor proficiency ( 0 to $\leq 25 \%)$ are more likely to have poor health-related fitness. Interestingly, the relationship between Fine Manual Control and $\mathrm{VO}^{2}$ peak changed from weak and non-significant in the Total group to a very strong negative relationship for children in the $1^{\text {st }}$ Motor Quartile group. This is despite there being no significant difference in $\mathrm{VO}^{2}$ peak between children in the $1^{\text {st }}$ Motor Quartile group compared to those in the $4^{\text {th }}$ Motor Quartile group. These findings warrant further investigation, however it should be acknowledged that this study cannot determine causation between motor proficiency and these health-related fitness measures. Further observational and intervention based studies with larger participant numbers are required to investigate if motor proficiency (fine and gross 
motor) can predict health-related outcomes or if intervening to improve certain aspects of motor proficiency will enhance health-related fitness in children.

By using a multiple regression analysis we were able to demonstrate that the motor subtests of Strength and Running Speed and Agility were the strongest contributors to the relationship between motor proficiency and the health-related measures of WC, BMI and cardiorespiratory fitness $\left(\mathrm{VO}_{2}\right.$ peak) and these results address the third of the study aims.

The findings of this study are unique, in that a wide range of fine and gross motor skills were investigated using the BOT2. Previous research investigating the relationship between fitness and motor proficiency $(4,13)$ used the Movement Assessment Battery for Children (MABC) and was only able to demonstrate relationships between the motor subcategories of Manual Dexterity, Ball Skills and Balance, which may or may not have been a consequence of the limited subtests within the MABC. The increased number of motor subtests available within the BOT2, facilitated a deeper investigation of the relationship between motor proficiency and health-related fitness measures. Furthermore, the direct measurement of cardiorespiratory fitness $\left(\mathrm{VO}^{2}\right.$ peak) of a representative subgroup of children in this study, and the subsequent investigation of its relationship with motor proficiency, in a healthy school-based general population cohort, provides a unique exploration of the relationship between children's motor proficiency with health and fitness that has not previously been reported for Australian children.

Considering the high prevalence of childhood obesity, the findings of this study are particularly relevant as strength and running speed and agility are fundamental to day to day activities in the playground and during sport and without proficiency in these areas, children are likely to be less active and more sedentary as evidenced in prior research (5). The overall findings of the present study are supported by previous research (4) that examined physical fitness in 9 and 10-year-old children, where the authors concluded that children with impaired motor skills displayed 
reduced physical fitness based on field testing, and subsequently hypothesised that the relatively poor performance-related fitness of children with movement difficulties, was due to lower levels of physical activity, indicating a spiralling 'chicken and egg' effect.

The present study had some potential limitations that should be considered in any future research in this area. Firstly, the study had more boys than girls and this may have influenced the overall results of the study, considering that there were significant differences between girls and boys for some health-related measures. Secondly, the study population was a relatively small sample size from a defined geographical region of Australia. Additionally, as parents ultimately decided to provide or not provide consent for their children to participate, it is possible that this may have biased the sample population for the study. Lastly, the study sample included two male participants with a diagnosis of ASD; a condition known to impact motor proficiency. Although their inclusion did not result in significant differences between male and female groups for motor proficiency, it may have impacted the correlations examined in the study and this should be considered in future research.

Overall, findings from this study suggest that motor proficiency, particularly strength and running speed and agility, once corrected for age, can predict health-related status for children. Motor proficiency and specifically strength and running speed and agility, should therefore be considered as a focus of investigation for children with poor health-related fitness, as motor incompetence could be an underlying contributing factor to a child's poor health. Further research is needed to investigate the generalisability of these findings to primary versus high school-aged children and to children from geographical regions outside of the study population. Longitudinal research is required to investigate if motor skills in early childhood can predict health status in later childhood or early adulthood and if targeted motor skill-related interventions in the primary school years can halt the progression to poor health and chronic disease. 


\section{Acknowledgements}

Thank you to Professor's Nancy Low Choy and Roger Hughes for their review of the study design and assistance with application for ethical approval. Thank you also to Dr Michael Simmonds for his assistance with incremental exercise testing. No external funding was secured for this study. Internal Funding from the Bond University Research Centre for Health, Exercise Science and Sport (BURCHESS) and the Faculty of Health Sciences and Medicine, Bond University was utilised to undertake this study.

\section{Financial Disclosure}

The authors have no financial relationships relevant to this article to disclose.

\section{Conflict of Interest}

The authors have no conflicts of interest to disclose.

\section{References}

1. Tomkinson GR, Leger LA, Olds TS, Cazorla G. Secular Trends in the Performance of Children and Adolescents (1980 - 2000). Sports Med. 2003; 33 (4): 285 - 300.

2. Wedderkopp N, Froberg K, Hansen HS, Andersen, LB. Secular trends in physical fitness and obesity in Danish 9-year-old girls and boys: Odense School Child Study and Danish substudy of the European Youth Heart Study. Scand J Med Sci Sports. 2004; 14 (3); 150 155.

3. Andersen L, Harro M, Sardinha LB, Froberg K, Ekelund U, Brage S, Anderssen SA. Physical activity and clustered cardiovascular risk in children: a cross-sectional study (The European Youth Heart Study). Lancet. 2006; 368: 299-304. 
4. Haga M. The relationship between physical fitness and motor competence in children. Child Care, Health Dev, 2008a; 34(3): 329-334.

5. Wrotniak B, Epstein L, Dorn J, Jones K, Kondilis V. The relationship between motor proficiency and physical activity in children. Pediatrics; 2006; 118 (6):1758-1765.

6. Cantell M., Crawford S. and Tish Doyle-Baker P. Physical fitness and health indices in children, adolescents and adults with high or low motor competence. Hum Mov Sci; 2008; 27(2):344-62

7. Haga M. Physical fitness in children with movement difficulties. Physiotherapy; 2008b; 94: 253-259.

8. Okely A, Booth M, Chey T. Relationships between body composition and fundamental movement skills among children and adolescents. Res Q Exerc Sport; 2004; 75(3):238-47.

9. Petrolini N, Iughetti L, Bernasconi S. Difficulty in visual motor coordination as a possible cause of sedentary behaviour in obese children. Int J Obes Relat Metab Disord. 1995; 19:928.

10. Okely AD and Booth ML. Relationship of enjoyment of physical activity and preferred activities to fundamental movement skills in young children. International Journal of Behavioural Medicine; 2000; 7:S151.

11. Centers for Disease Control and Prevention Web site (Internet). CDC Growth charts, (cited 2014 May 12); Available from: http://www.cdc.gov/growthcharts/

12. Bruininks RH, Bruininks BD. Bruininks Oseretsky Test of Motor Proficiency: Examiners Manual, 2nd ed. (BOT-2). Minneapolis, MN: NCS Pearson; 2005. 263 p.

13. Haga M. Physical fitness in children with high motor competence is different from that in children with low motor competence. Phys Ther; 2009; 89:1089-109 


\section{Figure Legend}

Figure 1. Waist Circumference and BMI for BOT2 Total Motor Proficiency quartile groups.

BOT2 - Bruininks Oseretsky Test of Motor Proficiency. Sub groups defined by the following criteria.

1. $1^{\text {st }}$ Motor Quartile - BOT2 Quartile Standard Score (0 to $\left.\leq 25 \%\right)$

2. $2^{\text {nd }}$ Motor Quartile - BOT2 Quartile Standard Score $(>25 \%$ to $\leq 50 \%)$

3. $3^{\text {rd }}$ Motor Quartile - BOT2 Quartile Standard Score ( $>50 \%$ to $\left.\leq 75 \%\right)$

4. $4^{\text {th }}$ Motor Quartile - BOT2 Quartile Standard Score $(>75 \%$ to $\leq 100 \%)$

*Sidaks post hoc test is significant at the 0.05 level. 


\section{Tables}

Table 1. Health-related fitness characteristics of study participants in total group and in $1^{\text {st }}$ and $4^{\text {th }}$ motor quartile subgroups.

Table 2. Motor performance-related fitness characteristics of study participants.

Table 3. Pearson's correlations between motor proficiencies and health-related fitness measures.

Table 4. Multiple regression coefficients between motor proficiency models and health-related fitness measures.

\section{Figures}

Figure 1. Waist Circumference and BMI for BOT2 Total Motor Proficiency quartile groups. 
Table 1 . Health-related fitness characteristics of study participants in total group and in $1^{\text {st }}$ and $4^{\text {th }}$ motor quartile subgroups.

\begin{tabular}{|c|c|c|c|c|c|}
\hline \multirow{6}{*}{ Variable } & \multirow{5}{*}{ Total Group } & \multicolumn{3}{|l|}{ Difference } & \multirow{2}{*}{$\begin{array}{l}\text { Difference } \\
\text { between } 1^{\text {st }}\end{array}$} \\
\hline & & hetween & $1^{\text {st }}$ Motor & $4^{\text {th }}$ Motor & \\
\hline & & Males and & Quartile Group & Quartile Group & and $4^{\text {th }}$ Motor \\
\hline & & Females & $(n=13)$ & $(n=34)$ & Quartile \\
\hline & & & & & Groups \\
\hline & Mean \pm SD & p-value & Mean \pm SD & Mean \pm SD & p-value \\
\hline Height (cm) & $147.01 \pm 18.12$ & $0.048^{*}$ & $150.77 \pm 25.37$ & $140.16 \pm 11.61$ & 0.33 \\
\hline Weight (kg) & $42.66 \pm 23.55$ & $0.035^{*}$ & $56.37 \pm 45.17$ & $34.20 \pm 9.10$ & $0.02 *$ \\
\hline BMI $\left(\mathrm{kg} / \mathrm{m}^{2}\right)$ & $18.72 \pm 5.62$ & 0.091 & $22.25 \pm 11.24$ & $17.14 \pm 2.59$ & $0.03 *$ \\
\hline $\begin{array}{l}\text { BMI } \\
\text { (percentile) }\end{array}$ & $50.81 \pm 31.146$ & 0.379 & $60.69 \pm 33.03$ & $44.79 \pm 32.35$ & 0.54 \\
\hline z-BMI & $0.041 \pm 1.11$ & 0.388 & $0.44 \pm 1.39$ & $-0.18 \pm 1.14$ & 0.44 \\
\hline $\mathrm{WC}(\mathrm{cm})$ & $67.33 \pm 14.09$ & 0.052 & $76.19 \pm 24.78$ & $62.34 \pm 7.31$ & $0.01^{*}$ \\
\hline WC (\% range) & 50-75th & - & 75-90th & 25-50th & - \\
\hline $\begin{array}{l}\text { Resting HR } \\
\text { (beats/min) }\end{array}$ & $80.75 \pm 13.41$ & $<0.001^{*}$ & $76.19 \pm 24.78$ & $84.00 \pm 13.29$ & 0.26 \\
\hline $\begin{array}{l}\text { Resting Systolic } \\
\text { BP (mmHg) }\end{array}$ & $117.07 \pm 15.62$ & $0.028 *$ & $121.07 \pm 21.29$ & $112.44 \pm 12.37$ & 0.43 \\
\hline Resting & & & & & \\
\hline $\begin{array}{l}\text { Diastolic BP } \\
\text { (mmHg) }\end{array}$ & $69.68 \pm 11.51$ & 0.774 & $73.54 \pm 13.94$ & $65.65 \pm 10.13$ & 0.18 \\
\hline
\end{tabular}

Data presented as mean \pm SD. 
WC - Waist Circumference, HR - Heart Rate, BMI - Body Mass Index, BP - Blood Pressure $1^{\text {st }}$ Motor Quartile - BOT2 Quartile Standard Score ( 0 to $\left.\leq 25 \%\right)$

$4^{\text {th }}$ Motor Quartile - BOT2 Quartile Standard Score ( $>75 \%$ to $\left.\leq 100 \%\right)$

*Sidaks post hoc test is significant at the 0.05 level. 
Table 2. Motor performance-related fitness characteristics of study participants.

\begin{tabular}{|c|c|c|c|c|}
\hline BOT2 Variable (No.) & $\begin{array}{c}\text { Total Point } \\
\text { Score }\end{array}$ & Standard Score & Percentile Rank & $\begin{array}{c}\text { Difference } \\
\text { between Males } \\
\text { and Females }\end{array}$ \\
\hline$(n=77)$ & & Mean \pm SD & & p-value \\
\hline Fine Motor Precision & $37.77 \pm 3.99$ & N/A & N/A & .529 \\
\hline Fine Motor Integration & $35.79 \pm 4.60$ & N/A & N/A & .361 \\
\hline Fine Manual Control & N/A & $49.71 \pm 9.06$ & $48.16 \pm 27.67$ & - \\
\hline Manual Dexterity & $31.42 \pm 5.21$ & N/A & N/A & .233 \\
\hline Upper-Limb Coordination & $34.88 \pm 5.42$ & N/A & N/A & .469 \\
\hline Manual Coordination & N/A & $54.17 \pm 8.63$ & $62.25 \pm 26.59$ & - \\
\hline Bilateral Coordination & $21.87 \pm 3.42$ & $\mathrm{~N} / \mathrm{A}$ & $\mathrm{N} / \mathrm{A}$ & .053 \\
\hline Balance & $32.56 \pm 3.71$ & N/A & N/A & .399 \\
\hline Body Coordination & $\mathrm{N} / \mathrm{A}$ & $50.68 \pm 9.65$ & $51.46 \pm 29.54$ & - \\
\hline Running Speed and Agility & $37.77 \pm 6.00$ & N/A & N/A & .543 \\
\hline Strength & $29.90 \pm 5.47$ & N/A & N/A & .305 \\
\hline Strength and Agility & N/A & $58.04 \pm 8.36$ & $73.95 \pm 23.06$ & - \\
\hline Total Motor Proficiency & & $54.36 \pm 10.00$ & $61.68 \pm 29.06$ & - \\
\hline
\end{tabular}

Data presented as mean \pm SD. 
Table 3. Pearson's correlations between motor proficiencies and health-related fitness measures.

\begin{tabular}{|c|c|c|c|c|c|}
\hline BOT2 & RSBP & RDBP & Weight & BMI & WC \\
\hline \multirow[t]{3}{*}{ Standard Score (SS) } & (mmHg) & (mmHg) & (kg) & $\left(\mathrm{kg} / \mathrm{m}^{2}\right)$ & $(\mathrm{cm})$ \\
\hline & $r$ & $\mathrm{r}$ & $\mathrm{r}$ & $r$ & $\mathrm{r}$ \\
\hline & \multicolumn{5}{|c|}{ Total Group $(\mathrm{n}=77)$} \\
\hline \multirow[t]{2}{*}{ Fine Manual Control SS } & $-.321^{* *}$ & $-.279^{*}$ & $-.378^{* *}$ & $-.277^{*}$ & $-.383^{* *}$ \\
\hline & $(.004)$ & $(.014)$ & $(.001)$ & $(.015)$ & $(.001)$ \\
\hline \multirow[t]{2}{*}{ Manual Coordination SS } & -.174 & -.152 & $-.331^{* *}$ & $-.303^{* *}$ & $-.344^{* *}$ \\
\hline & $(.130)$ & $(.186)$ & $(.003)$ & $(.007)$ & $(.002)$ \\
\hline \multirow[t]{2}{*}{ Body Coordination SS } & -.141 & -.087 & -.144 & -.134 & -.146 \\
\hline & $(.221)$ & $(.454)$ & $(.213)$ & $(.245)$ & $(.204)$ \\
\hline \multirow[t]{2}{*}{ Strength and Agility SS } & $-.274^{*}$ & -.156 & $-.460^{* *}$ & $-0.480^{* *}$ & $-.537^{* *}$ \\
\hline & $(.016)$ & $(.174)$ & $(<.001)$ & $(<.001)$ & $(<.001)$ \\
\hline \multirow[t]{2}{*}{ Total Motor SS } & $-.288^{*}$ & $-.232^{*}$ & $-.392^{* *}$ & $-.356^{* *}$ & $-.431^{* *}$ \\
\hline & $(.011)$ & $(.042)$ & $(<.001)$ & $(.001)$ & $(<.001)$ \\
\hline \multicolumn{6}{|c|}{1 st Motor Quartile Group $(0 \%$ to $\leq 25$ th $)(n=13)$} \\
\hline \multirow[t]{2}{*}{ Fine Manual Control SS } & -.493 & -.447 & -.216 & -.073 & -.204 \\
\hline & $(.087)$ & $(.126)$ & $(.478)$ & $(.812)$ & $(.503)$ \\
\hline \multirow[t]{2}{*}{ Manual Coordination SS } & -.091 & -.122 & -.408 & -.396 & -.436 \\
\hline & $(.768)$ & $(.690)$ & $(.167)$ & $(.180)$ & $(.136)$ \\
\hline \multirow[t]{2}{*}{ Body Coordination SS } & -.310 & .016 & -.036 & -.036 & .540 \\
\hline & $(.303)$ & $(.959)$ & $(.908)$ & $(.908)$ & $(.057)$ \\
\hline \multirow[t]{2}{*}{ Strength and Agility SS } & -.488 & .037 & $-.701^{* *}$ & $-.723^{* *}$ & $-.745^{* *}$ \\
\hline & $(.090)$ & $(.904)$ & $(.008)$ & $(.005)$ & $(.003)$ \\
\hline \multirow[t]{2}{*}{ Total Motor SS } & $-.721^{* *}$ & -.141 & $-.739^{* *}$ & $-.631^{*}$ & $-.769^{* *}$ \\
\hline & $(.005)$ & $(.646)$ & $(.004)$ & $(.021)$ & $(.002)$ \\
\hline
\end{tabular}

Pearson's Correlation Coefficients - significance level for each value is shown in brackets. 
**Pearson Correlation is significant at the 0.01 level (2-tailed).

*Pearson Correlation is significant at the 0.05 level (2-tailed).

RSBP - Resting Systolic Blood Pressure, RDBP - Resting Diastolic Blood Pressure, BMI - Body Mass Index, WC - Waist Circumference. 
Figure 1. Waist Circumference and BMI for BOT2 Total Motor Proficiency quartile groups.
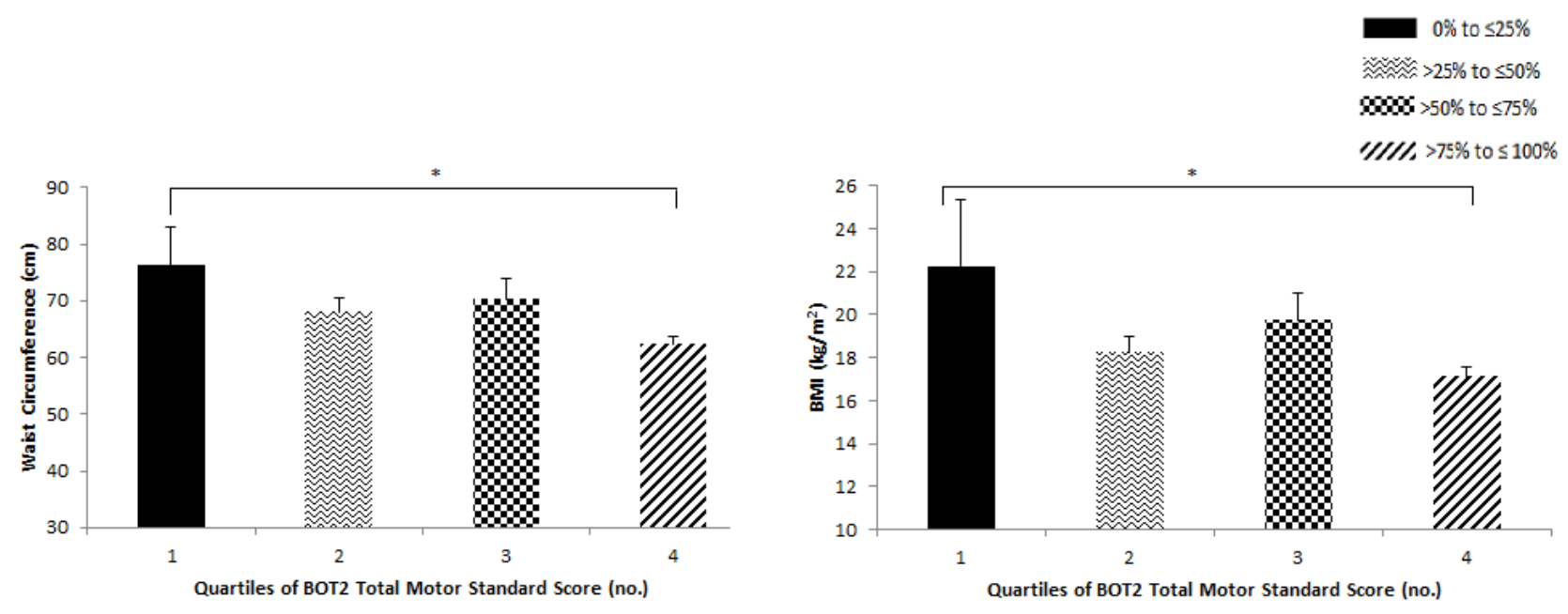

1. $1^{\text {st }}$ Motor Quartile - BOT2 Quartile Standard Score ( 0 to $\left.\leq 25 \%\right)$

2. $2^{\text {nd }}$ Motor Quartile - BOT2 Quartile Standard Score ( $>25 \%$ to $\left.\leq 50 \%\right)$

3. $3^{\text {rd }}$ Motor Quartile - BOT2 Quartile Standard Score ( $>50 \%$ to $\left.\leq 75 \%\right)$

4. $4^{\text {th }}$ Motor Quartile - BOT2 Quartile Standard Score ( $>75 \%$ to $\left.\leq 100 \%\right)$

*Sidaks post hoc test is significant at the 0.05 level. 